\title{
Поисково-оценочные работы на ультракалиевые породы Забайкалья (сынныриты) для производства минеральных удобрений
}

\author{
Рыцк А.Ю. ${ }^{1}$, Каюков А.Е. ${ }^{1}$, Пестриков А.А. ${ }^{2}$, Быстрицкий А.О. ${ }^{1}$, Осташева М.А. ${ }^{1}$, Маев И.О. ${ }^{1}$, \\ Хвалёв В.В. ${ }^{1}$, Иващенкова О.В. ${ }^{1}$, Смыслов С.А. ${ }^{1}$, Фёдоров М.М. ${ }^{1}$ \\ IOOO «Байкал Недра Гео», Санкт-Петербург, сео@bngeo.com; ak@bngeo.com; a.bystritsky@bngeo. \\ com; m.ostasheva@bngeo.com; i.maev@bngeo.com; hvalev@bngeo.com; ivaschenkova@bngeo.com; \\ petra@bngeo.com;m.fedorov@bngeo.com \\ 20ОО «Инжиниринг минеральных ресурсов», Санкт-Петербург, apestrikoff@gmail.com
}

Аннотация. В статье рассмотрены основные цели поисково-оценочного этапа геологоразведочных работ на высококалиевые сынныриты участка недр Калюмный, респ. Бурятия, РФ. Приведены основные результаты работ по состоянию на февраль 2020 года и охарактеризованы способы определения химического состава пород, слагающих Сыннырский ультращелочной массив. Выполнено сопоставление результатов определения оксида калия ICPMS по HCAM-487-хс и с помощью портативного XRF - анализатора Vanta.

Ключевые слова: щелочные породы, сыннырит, калий, аналитика, Забайкалье.

\section{Scopind studygeological work on ultra-potassium rocks of Transbaikalia (synnyrites) for the production of SOP}

Rytck A.Y. ${ }^{1}$, Kayukov A.E. ${ }^{1}$, Pestrikov A.A. ${ }^{2}$, Bystritsky A.O. ${ }^{1}$, Ostasheva M.A. ${ }^{1}$, Mayev I.O. ${ }^{1}$, Khvalev V.V. ${ }^{1}$, Ivaschenkova O.V. ${ }^{1}$, Smyslov S.A. ${ }^{1}$, Fedorov M.M. ${ }^{1}$

${ }^{1} L L C « B N G »$, Saint-Petersburg,ceo@bngeo.com;ak@bngeo.com; a.bystritsky@bngeo.com; m.ostasheva@ bngeo.com;i.maev@bngeo.com; hvalev@bngeo.com; ivaschenkova@bngeo.com; petra@bngeo.com; m.fedorov@bngeo.com

${ }^{3}$ LLC «EMR», Saint-Petersburg, apestrikoff@gmail.com

Abstract. The article presents the main goals of the scoping study stage of geological exploration for ultrapotassium synnyrites of the Kalyumny area, Buryatia, Russia. The main results of the work as of February 2020 are presented and methods for determining the chemical composition of rocks composing the Synnyr ultra-alkaline massif are described. Comparison of results of determination of potassium oxide ICPMS by NSAM-487 and using a portable XRF analyzer Vanta was performed.

Key words: alkaline rocks, synnyrite, potassium, analytics, Transbaikalia.

\section{Введение}

В настоящей статье приведены геологические задачи и основные результаты, полученные за первые два года реализации комплекса поисково-оценочных работ, проведенных в рамках проекта по вовлечению в промышленную разработку специфических высококалиевых щелочных пород - сынныритов.

Впервые присутствие нефелиновых сиенитов в Забайкалье было установлено в 90-х годах $\mathrm{XX}$ века, однако отнесены эти породы были к одной из составляющих гранитного интрузивного комплекса (ныне выделяется как Конкудеро-Мамаканский). В 20-30-х годах прошлого века при составлении геологической карты масштаба 1:1000000 на территорию Мамского горнорудного района Г.В. Дитмаром фельшпатоидные сиениты были определены в самостоятельную геологическую формацию, однако масштабы их распространения так и остались не выясненными. С конца 50-х годов XX века началось систематическое геологическое изучение северо-восточной части Байкальской складчатой системы научной группой ВСЕГЕИ под руководством Л.И. Салопа, в работе которой принимал активное участие А.Я. Жидков, который и выделил на этой территории Северобайкальскую провинцию щелочных и фельшпатоидных сиенитов, насчитывающую более 15-ти разнообразных по форме и составу интрузивных тел, составил первые геологические карты наиболее крупных Сыннырского (около 600 кв. км.) и Бурпалинского (около 200 кв. км.) массивов. Кро- 
ме того, этим автором были открыты ультракалиевые кальсилит-нефелиновые сиениты, получившие название сынныриты. Основным полезным компонентом сыннырита является кальсилит - калиевый аналог нефелина.

В 1979 году на базе Северобайкальской ГРЭ ПГО Бурятгеология была образована Сыннырская партия, приступившая к поисково-оценочным работам на наиболее перспективных участках распространения ультракалиевых пород. Была выполнена проходка канав и проведено сплошное опробование их полотен, а также большой объем маршрутных геологических и геофизических исследований. В результате для участка Калюмный была составлена геологическая карта масштаба 1:10000, подсчитаны запасы потенциального калийно-глиноземного сырья по категории $\mathrm{C}_{2}$ в количестве 679 млн. т. и прогнозные ресурсы категории $\mathrm{P}_{1}$ в количестве 1.85 млрд.т., однако ввиду отсутствия изучения рудных залежей на глубину запасы приняты не были. Среднее содержание $\mathrm{K}_{2} \mathrm{O}$ в сынныритах составило 18.4 масс. \%, $\mathrm{Al}_{2} \mathrm{O}_{3}-22.9$ масс. \% (Ушаков, 1986).

Основным направлением технологических исследований советского периода являлось изучение агрохимических свойств молотого сыннырита - предполагалось внесение его в непосредственно в почву в качестве бесхлорного калийного удобрения, была показана его более низкая эффективность по сравнению с традиционными типами калийных удобрений, что предполагалось компенсировать пролонгированностью действия.

В 2016 году лицензию на разведку и добычу сыннырита на участке недр «Калюмный» приобрело ООО «Байкал Недра Гео» (г. Санкт-Петербург), которое сформировало геологическую службу для проведения работ по лицензии. Целью проведения оценочных и разведочных работ на участке является точное установление пространственных границ распространения тел сынныритов для подсчета запасов и изучение вещественного состава сынныритов для разработки экономически эффективной технологии получения понятных рынку товарных калийных удобрений и глиноземного сырья.

В отечественной геологоразведочной практике к настоящему времени сложилась устойчивая система проведения геологоразведочных работ (ГРР) в строгом соответствии с инструкциями и разнообразными методическими рекомендациями, которые разработаны отраслевыми институтами для всех видов полезных ископаемых и всех стадий работ. Сынныриты являются уникальными породами и ранее не вовлекались не только в промышленную разработку, но и в полноценный геологоразведочный процесс, соответственно на данный вид сырья отсутствуют надежные методические основы оценочных и разведочных работ, на которые можно было бы ориентироваться исполнителям.

Для заверки результатов ранее проведенных поисковых работ и прослеживания тел сынныритов на глубину была разработана собственная программа работ, которая включала заверку результатов ранее проведенных ГРР, сгущение сети канав на участке, заверку распространения тел сынныритов на глубину, аналитические и технологические исследования. Технологические и аналитические исследования проводятся в течении всего этапа оценочных работ, а непосредственно полевые работы были спланированы в следующей последовательности:

- проходка и переопробование старых канав, пройденных через 200-400 метров по простиранию тел сынныритов с целью заверки результатов исторического опробования;

- заверка и опробование тел сынныритов на глубину по сети 800-400×200 для подсчета запасов категории $\mathrm{C}_{2}$ и по сети $200 \times 200$ метров для подсчета по категории $\mathrm{C}_{1}$;

- заверка рудных тел канавами по простиранию и бурение скважин на флангах для оценки прогнозных ресурсов.

Для проходки канав первого этапа и сгущения сети была сохранена ориентировка канав предшественников, а бурение скважин было запланировано по этим же профилям, но таким образом, чтобы получить полностью перекрытый геологический разрез, как в случае подтверждения субвертикального падения рудных тел в сторону центра сыннырского массива, так и в случае их более пологого залегания или выклинивания с глубиной.

Проведенные в течение первого полевого сезона заверочные работы по историческим канавам в целом подтвердили как положение тел сынныритов в плане, так и их качественные характеристики, однако бурение первых же скважин полностью перевернуло представление исполнителей о гео- 
логическом строении участка - тела сынныритов, прослеженные от выходов на поверхность падают на С3 к центру массива под углами от $40^{\circ}$ до практически горизонтального залегания (рис. 1). Дальнейшее наращивание площади заверки бурением полностью подтвердило данные выводы и окончание запланированного комплекса буровых и горнопроходческих работ позволит надежно определить морфологические параметры сынныритовых тел и подсчитать запасы сырья с высокой степенью достоверности.

Одной из ключевых проблем при планировании работ являлся выбор оптимального способа определения содержаний полезных компонентов $\left(\mathrm{K}_{2} \mathrm{O}\right.$ и $\left.\mathrm{Al}_{2} \mathrm{O}_{3}\right)$, а также их кислоторастворимых форм в пробах из пород сыннырского массива. В соответствии с требованиями ФБУ «ГКЗ РФ» для подсчета запасов полезных ископаемых допускается применение только аналитических результатов, которые получены по методикам измерений не ниже III категории точности в аттестованных лабораториях, в область аккредитации которых данные методики включены.

Наиболее подходящей по точности, времени и стоимости методикой определения основных породообразующих компонентов в горных породах на данный момент является ICP-AES(HCAM 487-хс). На момент подготовки работ методика 487-хс определяла верхний предел обнаружения $\mathrm{K}_{2} \mathrm{O}$ в горных породах в 10 масс. \%, а по результатам исторических работ в сынныритах были установлены содержания оксида калия до 24 масс. \%. До начала поисково-оценочной стадии работ имеющийся у исполнителей каменный материал был передан в отдел метрологии ФГБУ ВИМС для исследований на возможность расширения верхнего предела обнаружения оксида калия. В результате проведенных работ методика НСАМ 487-хс была выпущена в редакции 2018 года с верхним пределом обнаружения $\mathrm{K}_{2} \mathrm{O}$ в 25 масс. \%.

Вторым направлением подготовки поисково-оценочных работ по количественным методам анализа стала разработка отделом метрологии ФГБУ «ВИМС» специально для данного проекта методики определения кислоторастворимых (kr) форм оксида калия и оксида алюминия в сынныритах. Определение кислоторастворимых форм полезных компонентов является крайне важным аспектом для данного проекта по причине того, что детально разработана технология сернокислотного выще-

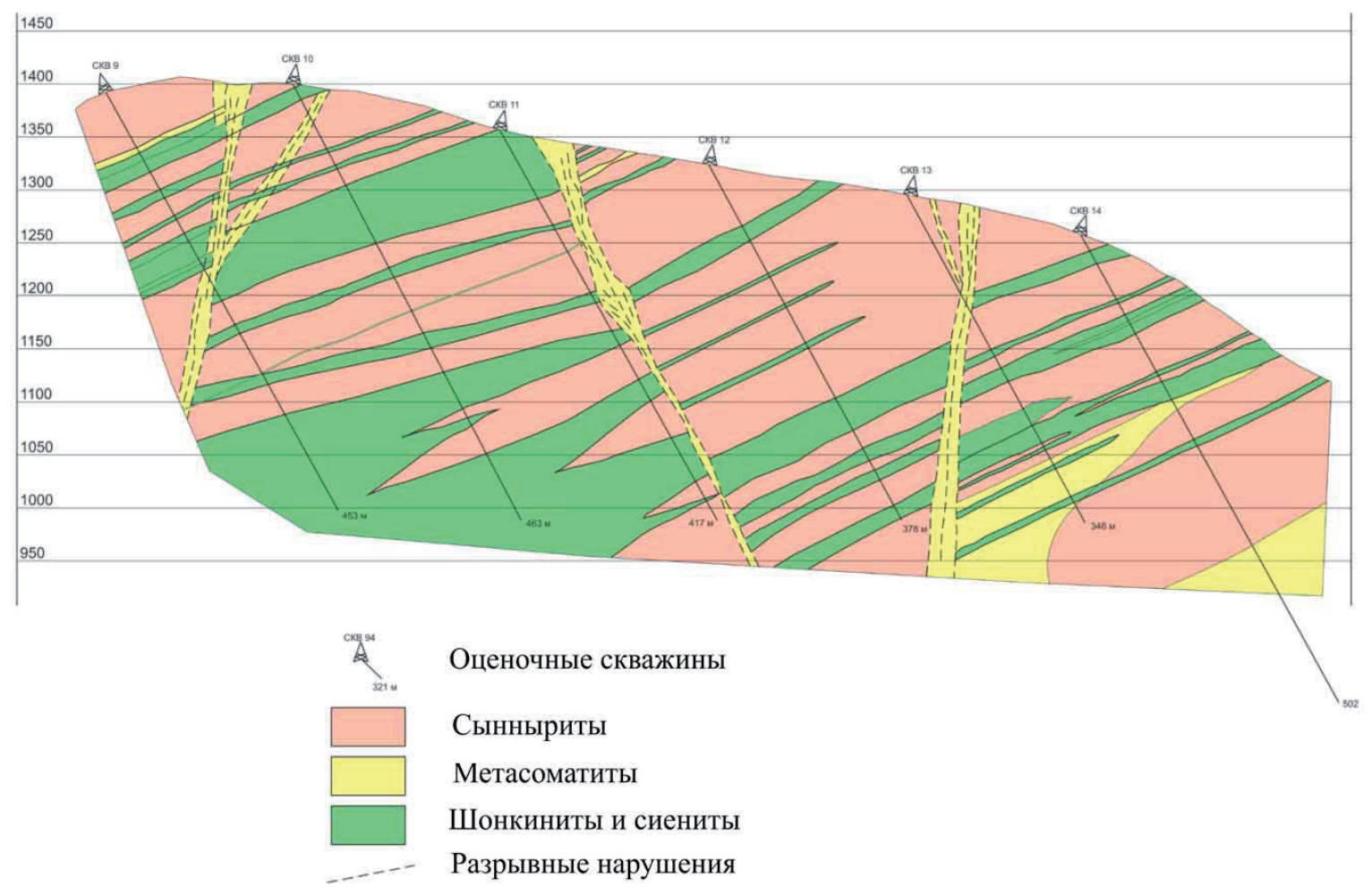

Рис. 1. Схематический геологический разрез по профилю скважин.

Fig. 1. Schematic geological section of the drill holes profile. 
лачивания растворимых форм калия и алюминия из сынныритов в раствор с осаждением глинозема и последующим восстановлением из раствора сульфата калия (товарного удобрения). В настоящее время ведется разработка экономически эффективной технологии полного вскрытия сынныритов с целью извлечения всего содержащегося в породе калия и алюминия (а не только их кислоторастворимых форм) в товарную продукцию. По результатам методических работ ФГБУ «ВИМС» разработана методика HCAM 555-хс (также ICP-AES) III категории точности с верхними пределами обнаружения для $\mathrm{K}_{2} \mathrm{O} \_\mathrm{kr}$ в 10 масс. \%, для $\mathrm{Al}_{2} \mathrm{O}_{3}$ kr в 50 масс. \%.

По содержанию основного полезного компонента $-\mathrm{K}_{2} \mathrm{O}$ (рис. 2) четко выделяется три выборки проб - в диапазонах 4-11.5, 11.5-16.5 и наиболее многочисленная - от 16.5 до 20.0 масс.\%. Результаты определения калия четко коррелируют с литотипами пород, установленными при документации (практически не содержат «переходных» разностей). При этом по содержанию кислоторастворимых форм калия сынныриты определяются еще более четко за счет отсутствия кальсилита в других породах участка.

Проведение работ поисково-оценочной стадии подразумевает непрерывное опробование скважин и горных выработок по всей протяженности для надежного определения состава всех разновидностей пород с целью определения кондиционных лимитов для подсчета запасов по результатам технологических испытаний и экономических расчетов. Такой подход подразумевает раздельное опробование петрографических типов пород для получения объективной информации об их химическом составе и технологических свойствах.

Основные петрографические разности, слагающие породы массива на участке Калюмный (сынныриты, нефелиновые и щелочные сиениты, полевошпатовые местасоматиты и др.), несмотря на крайне различный химический состав, оказались часто визуально неотличимы при документации керна. Применение химических методов определения состава пород для целей их детальной документации в канавах и керне скважин и дальнейшего опробования оказывается невозможным в связи с большим объемом поступающего на опробование материала, а также дискретностью транспортировки проб с участка работ.

Для оперативного определения химического состава пород при документации и разметке границ опробования использовался портативный XRF-анализатор OlympusVanta. Для использования экспресс-анализа химического состава пород при документации керна была

разработана следующая методика: после раскладки керновых ящиков в документаторской и его оттайки и просушки, керновые ящики размечались по бортам и перегородкам штрихами по линейке через каждые 25 см. Далее оператор производил экспресс анализ керна по точкам строго напротив проставленных на перегородках меток, а рядом с метками маркером выписывал полученные содержания оксида калия, полная таблица определений всех элементов по всей скважине загружалась в базу данных по окончании смены.

По состоянию на 30.01.2020 г. XRF-анализатором проанализирован весь керн пробуренных на первом этапе скважин - 18200 пог.м., а из аналитической лаборатории к моменту написания статьи пришли результаты определения химического состава пород по 1274 рядовым пробам. Для оценки корректности определения содержания оксида калия XRF-анализатором и возможности его применения в дальнейшем для расчленения разреза и в качестве метода определения содержаний полезных компонентов выполнено сопоставление результатов, полученных экспресс-способом непосредственно при документации керна и по данным аналитической лаборатории ФГБУ «ВИМС» методом ICP-AES (HCAM 487-хс). Для корректности сопоставления результаты анализа были усреднены по отметкам начала и окончания интервалов рядового опробования.

На рисунке 3 приведены диаграмма рассеяния XRF-ICP и график квантилей (50 классов) для содержаний $\mathrm{K}_{2} \mathrm{O}$. На диаграмме рассеяния отмечается отличная сходимость между способами определения оксида калия - практически все точки расположены строго вдоль линии равенства, а коэффициент корреляции между способами составляет 0.97. Однако на графике квантилей по усредненным результатам по классам содержаний четко видно, что при содержаниях $\mathrm{K}_{2} \mathrm{O}$ до 13 масс. \%, определения XRF-способом завышают оценку содержаний в среднем на 8-10 

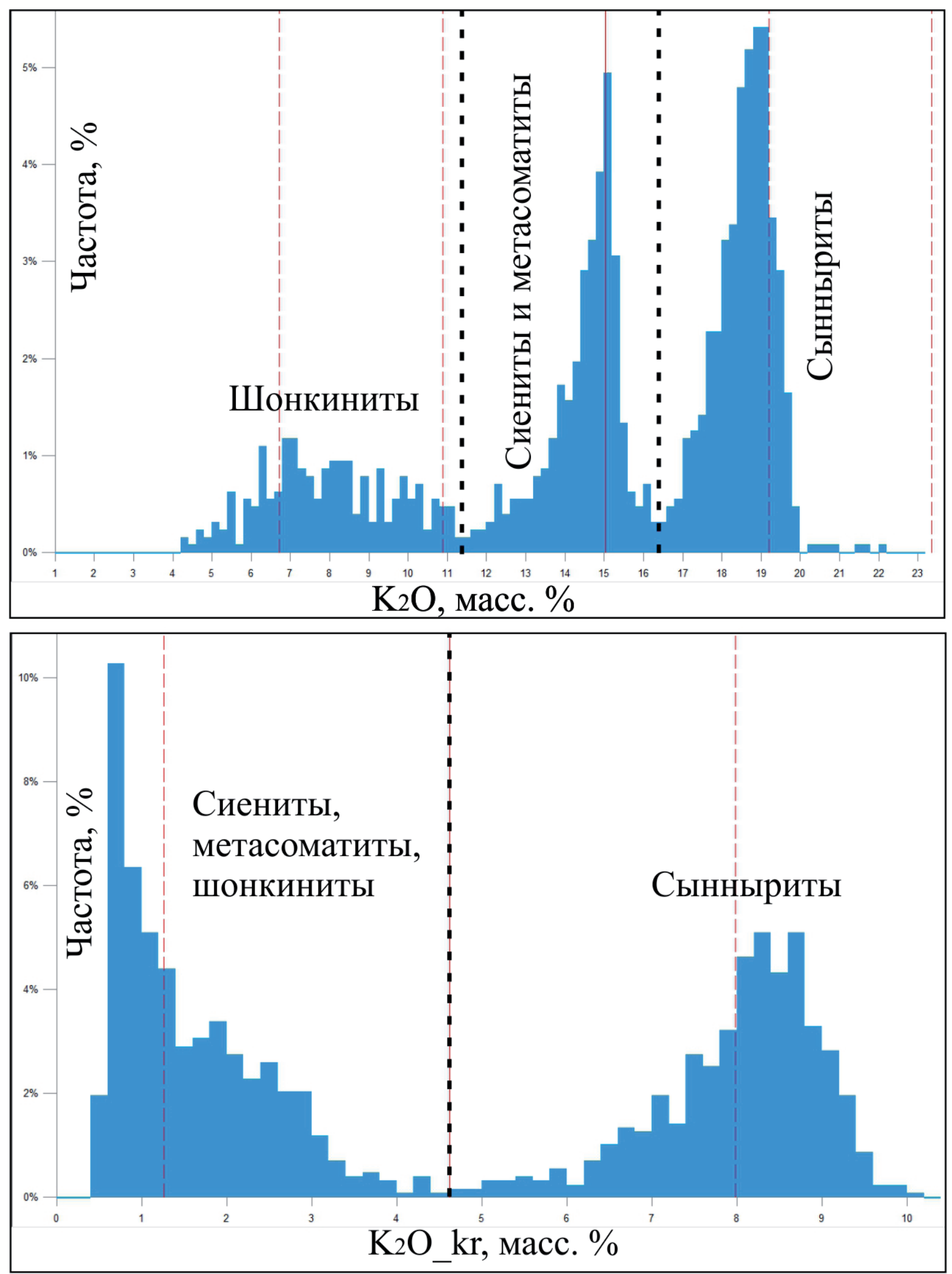

Рис. 2. Гистограмма распределения содержаний $\mathrm{K}_{2} \mathrm{O}\left(\right.$ верх) и распределения $\mathrm{K} \_\mathrm{kr}($ низ) в породах участка. Fig. 2. Histogram of the distribution of $\mathrm{K}_{2} \mathrm{O}$ (top) and $\mathrm{K}_{-} \mathrm{kr}$ (bottom) contents in the rocks of the site. 

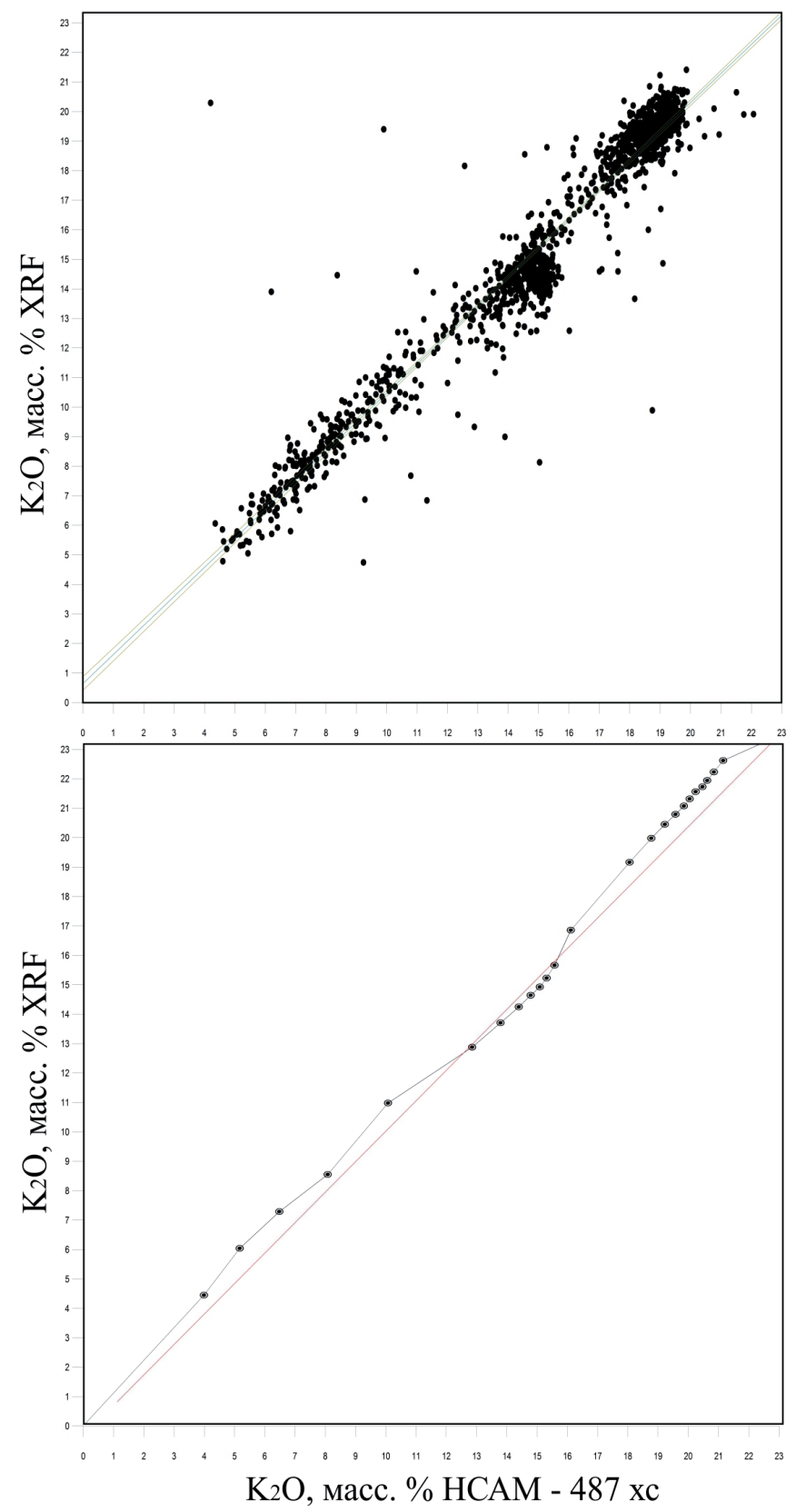

Рис. 3. Диаграмма рассеяния точек содержаний $\mathrm{K}_{2} \mathrm{O}$ по данным химического анализа НСАМ-487 хс и по данным ЧКА-анализатора (верх) и график квантилей по тем же показателям (низ).

Fig. 3. The scattering diagram of $\mathrm{K}_{2} \mathrm{O}$ content points according to the chemical analysis of NSAM-487 XC and according to the XRF analyzer (top) and the quantile graph for the same indicators (bottom). отн. \%, в диапазоне от 13 до 15 масс \%, наоборот, происходит занижение содержаний оксида калия на 1-3 отн. \%, а в классе свыше 15 масс. \% вновь происходит занижение содержаний относительно лабораторных на 1-2 отн. \%. Точки изменения знака отклонения определения способом XRF от ICP c занижения на завышение содержаний и обратно хорошо коррелируют с границами классов $\mathrm{K}_{2} \mathrm{O}$, выделенными на гистограмме распределения его содержаний по всей выборке проб, которые соответствуют породным разновидностям - до 11.5 масс. \% - шонкиниты, с 11.5 до 16.5 масс. \% - сиениты и метасоматиты, свыше 16.5 масс. \% - «собственно сынныриты».

В целом, несмотря на незначительные, но систематические отклонения результатов определения оксида калия экспресс-способом, результаты могут быть успешно использованы для документации керна и разметки границ рядового опробования, которое уже направляется в аналитическую лабораторию на химический анализ, результаты которого могут быть использованы при подсчете запасов. Методичное использование экспресс-анализатора по размеченным интервалам позволит по итогу оценочных работ накопить обширный статистический материал и при проведении разведочных работ использовать данный способ в качестве основного для оперативного выделения рудных интервалов при документации, что позволяет существенно сэкономить время и средства на проведении аналитических работ, направляя на химический анализ только рудные пробы и незначительное количество околорудных вмещающих пород.

\section{Заключение}

В результате выполнения буровых работ первого этапа установлено пологое залегание тел сынныритов среди вмещающих шонкинитов и сиенитов. Для корректного определения химического состава пород участка разработана (расширена) ICPMS методика определения высоких содержаний оксида калия и алюминия, а также их кислоторастворимых форм. Для оперативного определения химического состава пород при геологической документации керна показана возможность применения портативного XRF-анализатора Vantac с приемлемой точностью.

Реализация запланированных на поисково-оценочной стадии геологоразведочных работ позволит произвести корректную качественную и количественную оценку запасов сынныритов на 
участке недр Калюмный, разработать эффективную технологию переработки руд в минеральные удобрения и произвести максимально рациональное планирование разведочных работ для вовлечения пород участка в промышленное освоение.

\section{Благодарность}

Вся работы выполняются за счет собственных средств ООО «Байкал Недра Гео». Авторы отмечают, что выполнение данных работ - усилия всех сотрудников компании ООО «Байкал Недра Гео». Авторы выражают благодарность предшественникам, всем своим друзьям, коллегам, близким и «TheCure» за вдохновение на написание данной статьи.

\section{Литература}

1. Ушаков А.А., Морозов С.И., Жидков А.Я. Результаты поисково-оценочных работ на комплексные калийно-глиноземные руды в пределах сыннырского щелочного массива. Отчет сыннырской партии 1979-86 гг. УДК 553.5\6.044.003.1 (571.54). 160 с. $18 \backslash 343$ с. 